\title{
Intake of water and different beverages in adults across 13 countries
}

\author{
I. Guelinckx ${ }^{1}$ C. Ferreira-Pêgo ${ }^{2,3}$ - L. A. Moreno ${ }^{4}$ - S. A. Kavouras ${ }^{5}$ J. Gandy ${ }^{6,7}$. \\ H. Martinez ${ }^{8,9}$ - S. Bardosono ${ }^{10}$ • M. Abdollahi' ${ }^{11}$ - E. Nasseri ${ }^{11}$ • A. Jarosz ${ }^{12}$. \\ G. Ma ${ }^{13,14} \cdot$ E. Carmuega ${ }^{15} \cdot$ N. Babio ${ }^{2,3} \cdot$ J. Salas-Salvadó ${ }^{2,3}$
}

Received: 26 May 2015 / Accepted: 3 June 2015 / Published online: 14 June 2015

(C) The Author(s) 2015. This article is published with open access at Springerlink.com

\begin{abstract}
Purpose To describe the intake of water and all other fluids and to evaluate the proportion of adults exceeding the World Health Organisation (WHO) recommendations on energy intake from free sugar, solely from fluids.

Methods A total of 16,276 adults (46\% men, mean age 39.8 years) were recruited in 13 countries from 3 continents. A 24-h fluid-specific record over 7 days was used for fluid assessment.
\end{abstract}

This article is part of a supplement supported by Danone Nutricia Research.

Electronic supplementary material The online version of this article (doi:10.1007/s00394-015-0952-8) contains supplementary material, which is available to authorized users.

\section{J. Salas-Salvadó}

jordi.salas@urv.cat

1 Hydration and Health Department, Danone Research, Palaiseau, France

2 Human Nutrition Unit, Biochemistry Biotechnology Department, Faculty of Medicine and Health Sciences, Hospital Universitari de Sant Joan de Reus, IISPV (Institut d'Investigació Sanitària Pere Virgili), Universitat Rovira i Virgili, C/Sant Llorenç, 21, 43201 Reus, Spain

3 CIBERobn (Centro de Investigación Biomédica en Red Fisiopatología de la Obesidad y Nutrición), Institute of Health Carlos III, Madrid, Spain

4 GENUD (Growth, Exercise, NUtrition and Development) Research Group, Faculty of Health Sciences, Universidad de Zaragoza, Saragossa, Spain

5 Department of Health Human Performance and Recreation, University of Arkansas, Fayetteville, AR, USA

6 British Dietetic Association, Birmingham, UK

7 School of Life and Medical Services, University of Hertfordshire, Hatfield, UK
Results In Spain, France, Turkey, Iran, Indonesia and China, fluid intake was characterised by a high contribution of water (47-78\%) to total fluid intake (TFI), with a mean water intake between 0.76 and $1.78 \mathrm{~L} /$ day, and a mean energy intake from fluids from 182 to $428 \mathrm{kcal} /$ day. Between 11 and $49 \%$ of adults exceeded the free sugar WHO recommendations, considering solely fluids. In Germany, UK, Poland and Japan, the largest contributors to TFI were hot beverages (28-50\%) and water (18-32 \%). Mean energy intake from fluids ranged from 415 to $817 \mathrm{kcal} / \mathrm{day}$, and 48-62\% of adults exceeded free sugar WHO recommendations. In Mexico, Brazil and Argentina, the contribution of juices and regular sugar beverages (28-41\%) was as important as the water contribution to TFI (17-39\%).

8 RAND Corporation, Santa Monica, CA, USA

9 Hospital Infantil de Mexico Federico Gomez, Mexico City, Mexico

10 Department of Nutrition, Faculty of Medicine, Universitas Indonesia, Jakarta, Indonesia

11 Department of Nutrition Research, Faculty of Nutrition Sciences and Food Technology, National Nutrition and Food Technology Research Institute, Shahid Beheshti University of Medical Sciences, Tehran, Iran

12 National Food and Nutrition Institute, Warsaw, Poland

13 National Institute for Nutrition and Food Safety, Chinese Center for Disease Control and Prevention, Beijing, China

14 Department of Nutrition and Food Hygiene, School of Public Health, Peking University, Beijing, China

15 Centro de Estudios Sobre Nutrición Infantil, Buenos Aires, Argentina 
Mean energy intake from fluids ranged 565-694 kcal/day, and $60-66 \%$ of the adults exceeded the free sugar WHO recommendation.

Conclusions The highest volumes recorded in most of the countries were for water, mean energy intake from fluids was up to $694 \mathrm{kcal} / \mathrm{day}$, and $66 \%$ of adults exceeded the free sugar WHO recommendation solely by fluids. Actions to create an environment in favour of water consumption and reduce sugar intake from fluids therefore are warranted.

Keywords Water $\cdot$ Beverages $\cdot$ Fluids $\cdot$ Adult population . WHO recommendation $\cdot$ Energy intake $\cdot$ Free sugars

\section{Introduction}

Total fluid intake (TFI) or its biomarkers have been associated with health outcomes such as the recurrence of kidney stones, renal function, new-onset hyperglycaemia and the prevalence of some components of the metabolic syndrome [1-4]. Therefore, assessing the volume of TFI in populations is important from a public health perspective.

In addition, it is also important to assess the intake of different sources of fluids. During the last decades, the diversity of fluid types with different nutritional composition has increased substantially. These fluids contribute to total intake more than water (e.g. energy, minerals, additives or caffeine), raising the question of their impact on health. In fact, an analysis of NHANES data has demonstrated differences in the risk of chronic kidney disease (CKD) depending on the type of beverages consumed. A low intake of plain water was associated with an increased risk of CKD [adjusted OR for low vs. high intake of plain water $=2.36(95 \%$ CI 1.10-5.06)], whilst, compared with the highest intake of beverages besides plain water, a low intake was not associated with an increased risk [5].

One explanation for the different health impact of consumption of different fluid types could be due to differences in energy and nutrient content. Recently, different health institutions and nutrition societies have raised concern regarding an excessive intake of energy coming from free sugars, especially present in sugar-sweetened beverages [6]. A meta-analysis of randomised trials and prospective cohort studies showed that among free-living people with ad libitum diets, the intake of free sugars was a determinant of body weight; however, intake was assessed from both food and beverages [7]. In respect of the consumption of sugar-sweetened beverages, there is a substantial scientific evidence relating the frequent intake of this type of beverages and an increased risk of weight gain [8-10], becoming overweight or obese [11-14], developing metabolic syndrome [15-18], type 2 diabetes [19] or other health problems $[17,20,21]$ compared with non-regular consumers.
This can partly be explained, as described in some crosssectional and intervention studies, by the observation that frequent consumers of sugar-sweetened beverages had higher total energy intake [22-24]. Given the current obesity pandemic and the estimation by the WHO that diabetes will be the 7th leading cause of death in 2030 [25], it seems relevant to evaluate the daily intake of the different fluid types and their contribution to energy and sugar intake. A recent systematic literature review by Özen et al. [26] reported the fluid intake of adults from 18 different countries. Unfortunately, only $50 \%$ of the 38 surveys included in the review reported the intake of water [26]. In addition, inconsistencies in the study designs, dietary assessment methods used or classification of beverages and age categories limit the comparison of results between countries. Furthermore, most of the surveys designed were originated in the USA and Europe, and it is pertinent in order to have a better understanding of the TFI, types of beverages consumed, and energy and free sugar consumed from beverages to extend the geographical scope of such studies.

Therefore, the aim of the present analysis was: (a) to describe the intake of drinking water and all other type of beverages in adults from 13 countries in three continents including Latin America and Asia, (b) to report energy intake from beverages and (c) to assess the percentage of adults exceeding the $\mathrm{WHO}$ recommendations on free sugars intake.

\section{Methods}

\section{Design and study population}

The present analysis gathers original and published data collected in adults ( $\geq 18$ years) by 13 different cross-sectional surveys. The surveys were conducted in Latin America (Mexico [27], Brazil and Argentina), Europe (Spain [28], France, UK [29], Germany, Poland and Turkey) and Asia (Iran [30], China [31], Indonesia and Japan). Data collection of the individual surveys was performed between 2008 and 2014 by public (Iranian National Nutrition and Food Technology Research Institute, NNFTRI; and Chinese Centre for Disease Control, CDC) and private organisations. The primary objective of these surveys was to assess the intake of drinking water and different types of beverages. A detailed analysis of the volume of TFI (sum of drinking water and beverages of all types) of these 13 surveys can be found elsewhere [32].

A random recruitment of participants was performed in each country either from a database of volunteers for population surveys, or via systematic door-to-door recruitment until the quotas for age, gender, region, habitat and/or socio-economic characteristics in relation to the total country population were met. 
Individuals working in company advertising, marketing, market research, the media, the manufacture, distribution and/or sale of water and all kind of beverages were excluded from participation as these individuals might be more aware of their intakes of fluids. Individuals who were not able to read and write in the language of the questionnaire were not eligible to participate in the survey. Having a specific diagnosed disease and/or following a medically prescribed diet were additional exclusion criteria in UK, Iran and China. The surveys in Argentina, Poland and Japan also excluded participants who had taken part in a survey about non-alcoholic drinks in the previous 6 months. Participants who did not complete the full 7 days of the fluid record, participants reporting a mean total daily fluid intake below $0.4 \mathrm{~L} /$ day or higher than $6 \mathrm{~L} /$ day or those who had participated in a market research study in the previous 6 months were excluded from the analysis. Pregnancy or lactation was not a specific exclusion in the most countries, except in Iran and China.

The effective sample size for the present analysis was 16,276 participants. Individuals who agreed to be part of the survey received detailed information about the survey's objectives, what was expected from them, and information about the study's provisions to preserve confidentiality, risks and benefits, and a clear explanation about their option to participate voluntarily or not in the study. After being given a fully informed description of the study, following the principles of informed consent, participants were asked for their oral approval to participate. No monetary incentive was offered for taking part in the study. All data were recorded anonymously. Therefore, participants included in the data set cannot be identified, either directly or through identifiers. The survey protocol of the unpublished surveys was reviewed and approved by the University of Arkansas Review Board (ref. 14-12-376).

\section{Assessment of the different fluid types}

Participants were provided with a 24-h fluid-specific record to collect information on their intake of all fluid types over 7 consecutive days. The 7-day fluid-specific record was presented in the official country language. In all countries except France, Germany and Japan, a paper version of this 7-day fluid-specific record was delivered and explained to the participants during an initial interview at home. After a period of 7 days, the fluid record was collected from the participant's home by the researcher and checked with the participant. In France, Germany and Japan, participants completed the 7-day fluid-specific record online. On the morning of the first day, these participants received an electronic reminder with written instructions on how to fill in the fluid record. Paper memory cards were made available to the participants so that they could make notes during the day and subsequently complete the fluid record online. Both the paper and online records had the same structure; the participants were asked the type of the beverage, the volume of the intake, whether the beverage was consumed hot or cold, the reason for the intake, and where and when it was consumed. The questionnaire also asked whether the fluid was consumed by itself or with some food, but did not record the food consumed. To assist the participants in estimating how much fluid was consumed, a photographic booklet of standard fluid containers supported the records. The 13 surveys all used this method to assess the fluid intake and were referred to as Liq.In ${ }^{7}$ (abbreviation of Liquid Intake over 7 days).

\section{Classification of the fluid types}

The fluids recorded were classified into: water (tap and bottled water); milk and milk derivatives; hot beverages (coffee, tea and other hot beverages); juices; regular sweetened beverages (RSB) (carbonated and non-carbonated soft drinks, energy drinks, sports drinks and other sugared soft drinks); diet beverages (diet carbonated soft drinks, diet non-carbonated soft drinks, other diet soft drinks); alcoholic drinks and other beverages. A more detailed classification can be found in supplementary Table 1 of this paper. TFI was defined as the sum of all these categories. In UK, Poland, Indonesia and Japan, the intake of diet beverages was very small, and therefore, they were during the first data treatment included in the RSB category. In Argentina, Iran and Indonesia, only non-alcoholic beverages were recorded. In Spain and France, no fluids were classified into the group "Other beverages".

\section{Assessment of anthropometric variables}

Height in metres $(\mathrm{m})$ and weight in kilograms $(\mathrm{kg})$ were self-reported by participants, except in Poland, Iran and China where these variables were measured. The body mass index (BMI) was calculated $\left(\mathrm{kg} / \mathrm{m}^{2}\right)$. In Mexico, Brazil, Argentina, Indonesia and Japan, no anthropometric data were available.

\section{Calculation of energy and sugar intake from fluids}

Energy and sugar intake from different types of beverages was calculated using the updated USDA international food composition tables [33]. Because the quantity consumed of the types of beverages in the category "Other beverages" was very low and these fluids frequently had an unknown food composition, this category was disregarded for the energy and sugar analysis. The percentage of individuals consuming more than $10 \%$ of energy requirements as free sugar, as recommended by WHO, was calculated [6]. WHO 
strongly recommends the intake of free sugars to less than $10 \%$ of total energy intake and recently even suggested under conditions a further reduction in the intake of free sugars below $5 \%$ of total energy intake [6]. Total energy requirement could not be calculated due to missing data of participants' weight and height in some countries. Therefore, the food balance sheets from the Food and Agriculture Organisation (FAO) were consulted to retrieve the mean energy intake ( $\mathrm{kcal} / \mathrm{capita} / \mathrm{day})$ of the adult population of the countries included in this analysis, which is accepted for ecological studies [34]. This source, however, contained the mean energy intake for total population, not separated by gender. In order to assess the differences in adherence to the WHO recommendation on free sugar intake between genders, the theoretical recommended daily energy requirement published by the Institute of Medicine was used for total population, but not for each country [35].

\section{Statistical analysis}

Data are presented either as means and $95 \%$ confidence intervals (CI) for continuous variables, or as numbers and percentages for dichotomous variables. The mean intakes are estimated values of all participants, including nonconsumers. We compared the distribution of the selected characteristics between groups Student's $t$ tests for continuous variables. All statistical tests were two-tailed, and the significance level was set at $P<0.05$. A Bonferroni post hoc test was used to correct for multiple comparisons in the online resources 2 and 3. All analyses were performed using the SPSS software version 22.0 (SPSS Inc., Chicago, IL).

\section{Results}

The daily water and beverages intake of 16,276 participants (47\% men) of 13 countries was analysed in the present study. The baseline characteristics of the male and female participants are presented in Table 1. The mean age of the male and female participants was $40.6(40.3,40.9)$ and $39.2(38.9,39.5)$ years, respectively. The mean BMI of the male and female participants was $25.6(25.4,25.7)$ and $25.0(24.8,25.1) \mathrm{kg} / \mathrm{m}^{2}$, respectively.

The daily intakes of the different beverage types are presented in Table 2. Among the different fluid types, the highest volumes were observed for water intake, which ranged from $0.27 \mathrm{~L} /$ day in Japan to $1.78 \mathrm{~L} /$ day in Indonesia. The second type of fluid consumed in terms of volume was hot beverages, with a daily intake ranging from $0.12 \mathrm{~L} /$ day in Mexico to $1.03 \mathrm{~L} /$ day in UK. RSB was the third mostly fluid consumed with a daily intake ranging from $0.10 \mathrm{~L} /$ day in China to $0.57 \mathrm{~L} /$ day in Mexico.
Significant gender differences were inconsistently observed across countries for the daily intake of different types of beverages (supplementary Table 2). Water intake was significantly higher among women than men in Germany, Turkey and the total sample, whereas water intake was lower among women than men in Brazil. Women had a significantly higher milk intake then men in Brazil, Germany and the total sample. A higher intake among women than men was also observed for hot beverages in Mexico, Spain, France and Poland. The significant difference in RSB intake between genders was also inconsistent across countries. In Brazil, Spain and Germany, women consumed less RSB than men, whereas in France and China women consumed more RSB than men. The significant gender effect on diet beverages was consistent, yet only present in two countries: women consumed more diet beverages then men in Spain and France. The mean intake of alcoholic beverages was significantly higher among men than women in Mexico, Brazil, Spain, France, Germany, Poland and the total sample. Figure 1 represents the contribution (\%) of the different fluid types to TFI. Countries with similar contribution patterns can be identified. Indonesia, China, Spain, Iran, Turkey and France are countries with the largest contribution of water to TFI, ranging from 47 to $78 \%$. The second largest contributor to TFI, in all these countries, was hot beverages. A different pattern was observed in Mexico and Brazil. In these countries, the contribution of RSB and juices to TFI was as large as the water contribution to TFI. This was also the case of Argentina, where the contribution of juices and RSB is larger than the water contribution; however, hot beverages are the primary contributor to TFI in this country. A high contribution of hot beverages to TFI was also observed among Germany, Poland and UK. However, unlike in Argentina, the contribution of water to TFI was larger than the contribution of RSB and juices. The contribution of water, juices, RSB and alcoholic beverages to TFI was comparable in these three countries (Germany, Poland and UK). The largest contribution of hot beverages $(50 \%)$ and alcoholic beverages (14\%) to TFI was observed in Japan.

Table 3 shows the mean energy intake from fluids. Total mean energy intake of total fluid ranged from a minimum of $182 \mathrm{kcal} /$ day in Indonesia to a maximum of $817 \mathrm{kcal} /$ day in Germany. In the total sample, the highest mean energy intake came from the consumption of milk and derivatives, followed by alcoholic beverages and then hot beverages. In Germany, Brazil, Iran, China and Spain, the milk and derivatives consumption represented the highest energy intake of all fluid types $(299,220,182,110$ and $108 \mathrm{kcal} /$ day, respectively). In France and Japan, the highest energy intake came from alcoholic beverages (95 and $159 \mathrm{kcal} /$ day, respectively), whereas in UK, Poland and Turkey, hot beverages delivered the highest energy intake (205, 146 
Table 1 General characteristics of the study population, categorised by country and gender

\begin{tabular}{|c|c|c|c|c|c|c|c|c|c|}
\hline & \multirow[t]{2}{*}{$n(\%)$} & \multirow[t]{2}{*}{ Age (years) } & \multicolumn{4}{|c|}{ Age categories (years, \%) } & \multirow[t]{2}{*}{ Weight $(\mathrm{kg})$} & \multirow[t]{2}{*}{ Height (m) } & \multirow[t]{2}{*}{$\mathrm{BMI}\left(\mathrm{kg} / \mathrm{m}^{2}\right)$} \\
\hline & & & $18-29$ & $30-39$ & $40-49$ & $\geq 50$ & & & \\
\hline \multicolumn{10}{|c|}{ Mexico, 2012} \\
\hline Men & $574(38)$ & $38.6(37.4,40.0)$ & 35.5 & 18.3 & 17.2 & 28.9 & ND & ND & ND \\
\hline Woman & $924(62)$ & $38.3(37.5,39.2)$ & 33.0 & 22.3 & 21.0 & 23.7 & ND & ND & ND \\
\hline \multicolumn{10}{|c|}{ Brazil, 2008} \\
\hline Men & $941(49)$ & $34.5(33.8,35.2)$ & 39.5 & 25.3 & 25.4 & 9.8 & ND & ND & ND \\
\hline Woman & $983(51)$ & $34.7(34.0,35.4)$ & 36.8 & 27.7 & 25.5 & 10.0 & ND & ND & ND \\
\hline \multicolumn{10}{|c|}{ Argentina, 2009} \\
\hline Men & $241(47)$ & $37.1(35.3,38.8)$ & 38.6 & 21.6 & 18.3 & 21.6 & ND & ND & ND \\
\hline Woman & $266(56)$ & $37.8(36.2,39.4)$ & 36.5 & 20.7 & 17.3 & 25.6 & ND & ND & ND \\
\hline \multicolumn{10}{|c|}{ Spain, 2012} \\
\hline Men & $630(51)$ & $42.9(41.8,44.0)$ & 18.6 & 25.4 & 23.3 & 32.7 & $78.8(77.8,79.8)$ & $1.7(1.7,1.7)$ & $26.1(25.8,26.4)$ \\
\hline Woman & $610(49)$ & $43.0(41.9,44.1)$ & 19.5 & 21.5 & 26.2 & 32.8 & $65.2(64.3,66.1)$ & $1.6(1.6,1.6)$ & $25.1(24.7,25.4)$ \\
\hline \multicolumn{10}{|c|}{ France, 2012} \\
\hline Men & $804(52)$ & $47.6(46.5,48.6)$ & 15.7 & 16.8 & 18.4 & 49.1 & $80.5(79.6,81.5)$ & $1.7(1.7,1.8)$ & $26.1(25.8,26.4)$ \\
\hline Woman & $730(48)$ & $41.5(40.5,42.5)$ & 22.2 & 23.2 & 24.5 & 30.1 & $65.5(64.4,66.6)$ & $1.6(1.6,1.6)$ & $24.2(23.8,24.6)$ \\
\hline \multicolumn{10}{|l|}{ UK, 2010} \\
\hline Men & $371(41)$ & $46.3(44.7,47.9)$ & 16.7 & 20.8 & 20.2 & 42.3 & ND & ND & $28.8(28.2,29.5)$ \\
\hline Woman & $526(59)$ & $42.2(41.0,43.4)$ & 19.6 & 26.4 & 25.3 & 28.7 & ND & ND & $25.9(25.3,26.5)$ \\
\hline \multicolumn{10}{|c|}{ Germany, 2012} \\
\hline Men & $856(45)$ & $44.1(43.2,44.9)$ & 16.4 & 20.1 & 26.5 & 37.0 & $81.6(80.3,82.8)$ & $1.8(1.8,1.8)$ & $25.8(25.4,26.2)$ \\
\hline Woman & $1012(54)$ & $41.9(41.2,42.7)$ & 17.5 & 22.3 & 30.6 & 29.5 & $77.0(75.9,78.2)$ & $1.7(1.7,1.7)$ & $27.3(26.8,27.7)$ \\
\hline \multicolumn{10}{|c|}{ Poland, 2014} \\
\hline Men & $517(49)$ & $46.0(44.5,47.4)$ & 19.5 & 19.0 & 19.1 & 42.4 & $82.8(81.6,84.0)$ & $1.8(1.7,1.8)$ & $26.6(26.3,27.0)$ \\
\hline Woman & $545(51)$ & $46.2(44.8,47.6)$ & 19.4 & 20.7 & 16.5 & 43.3 & $70.1(68.9,71.3)$ & $1.6(1.6,1.7)$ & $25.5(25.1,25.9)$ \\
\hline \multicolumn{10}{|c|}{ Turkey, 2011} \\
\hline Men & $488(51)$ & $34.4(33.4,35.3)$ & 37.7 & 27.3 & 24.2 & 10.9 & $75.9(74.8,77.0)$ & $1.7(1.7,1.7)$ & $25.0(24.7,25.4)$ \\
\hline Woman & $473(49)$ & $34.3(33.4,35.3)$ & 38.5 & 27.9 & 22.6 & 11.0 & $65.8(64.6,67.1)$ & $1.6(1.6,1.6)$ & $25.0(24.5,25.5)$ \\
\hline \multicolumn{10}{|l|}{ Iran, 2011} \\
\hline Men & $283(49)$ & $37.3(35.8,38.8)$ & 36.7 & 24.0 & 19.4 & 19.8 & $79.3(77.7,81.0)$ & $1.7(1.7,1.8)$ & $25.8(25.3,26.2)$ \\
\hline Woman & $289(51)$ & $36.5(35.1,37.9)$ & 35.3 & 28.0 & 20.1 & 16.6 & $63.9(62.6,65.3)$ & $1.6(1.6,1.6)$ & $24.9(24.3,25.4)$ \\
\hline \multicolumn{10}{|c|}{ China, 2010} \\
\hline Men & $733(50)$ & $39.5(38.6,40.4)$ & 24.7 & 25.2 & 25.8 & 24.3 & $67.4(66.6,68.2)$ & $1.7(1.7,1.7)$ & $23.2(23.0,23.5)$ \\
\hline Woman & $733(50)$ & $39.3(38.5,40.2)$ & 24.7 & 25.6 & 25.8 & 23.9 & $55.9(55.3,56.5)$ & $1.6(1.6,1.6)$ & $22.1(21.9,22.3)$ \\
\hline \multicolumn{10}{|c|}{ Indonesia, 2012} \\
\hline Men & $444(32)$ & $35.5(34.3,36.7)$ & 39.4 & 25.7 & 16.9 & 18.0 & ND & ND & ND \\
\hline Woman & $922(68)$ & $35.1(34.4,35.8)$ & 39.3 & 28.5 & 17.6 & 14.6 & ND & ND & ND \\
\hline \multicolumn{10}{|c|}{ Japan, 2009} \\
\hline Men & $698(51)$ & ND & 26.6 & 27.4 & 21.5 & 24.5 & ND & ND & ND \\
\hline Woman & 683 (49) & ND & 26.1 & 27.1 & 21.1 & 25.8 & ND & ND & ND \\
\hline \multicolumn{10}{|c|}{ Total population $^{\mathrm{a}}$} \\
\hline Men & $7580(47)$ & $40.6(40.3,40.9)$ & 27.0 & 22.8 & 22.0 & 28.3 & $77.9(77.5,78.4)$ & $1.7(1.7,1.7)$ & $25.6(25.4,25.7)$ \\
\hline Woman & $8696(53)$ & $39.2(38.9,39.5)$ & 28.0 & 24.8 & 23.3 & 23.9 & $67.0(66.6,67.5)$ & $1.6(1.6,1.6)$ & $25.0(24.8,25.1)$ \\
\hline
\end{tabular}

Data expressed as mean $(95 \% \mathrm{CI})$ or percentage

$B M I$ body mass index, $N D$ no data

${ }^{\text {a }}$ Include only those countries with data available on the presented characteristics 


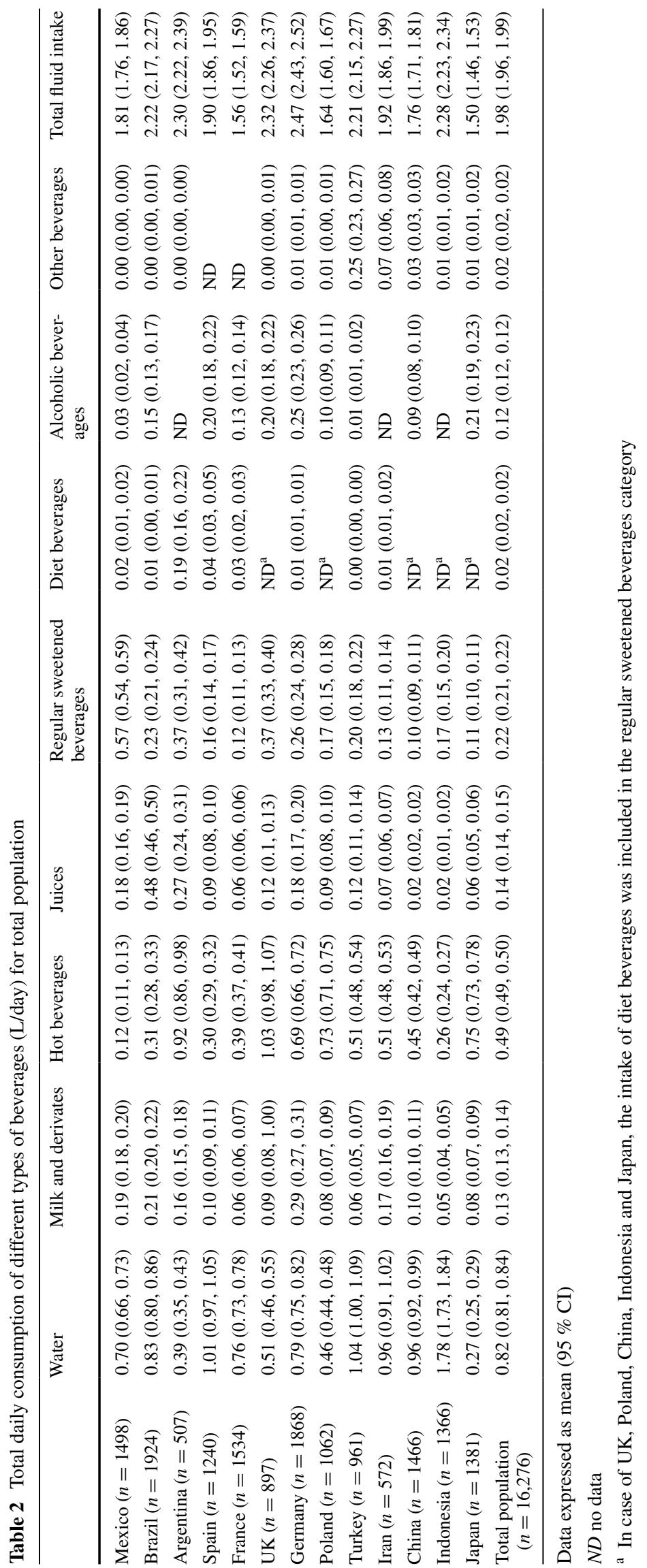


Fig. 1 Contribution of the different types of beverages to TFI stratified by country

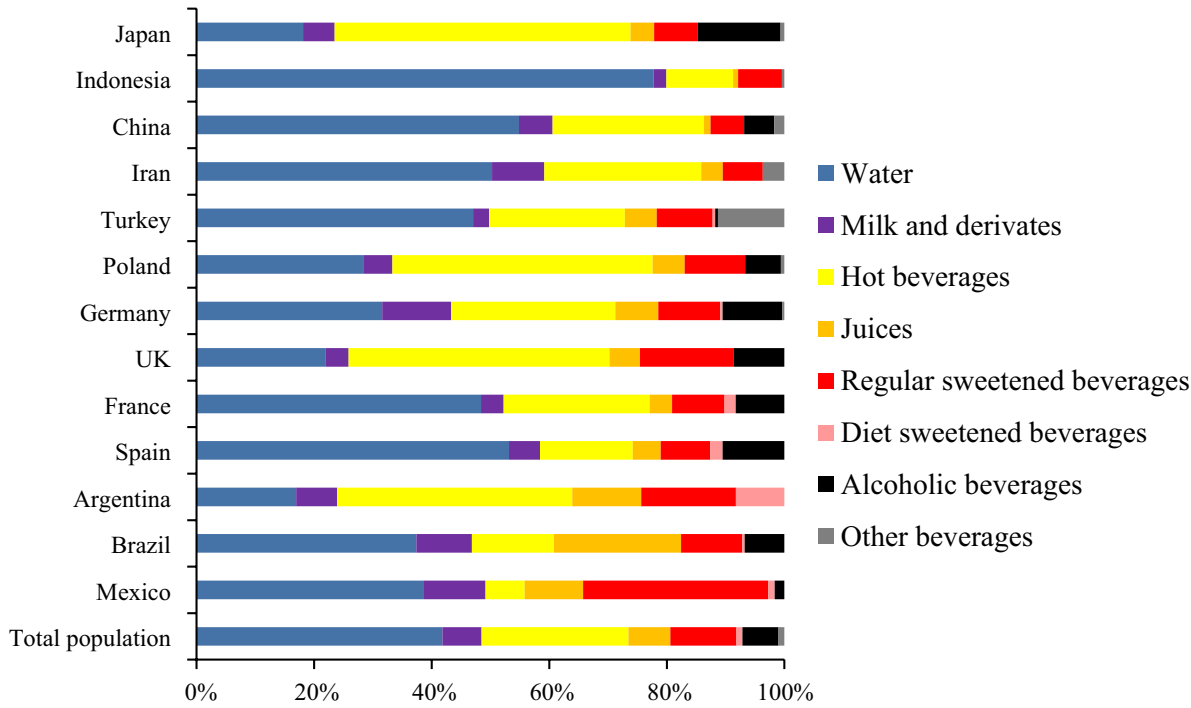

Table 3 Energy intake (in kcal) of different types of fluid intake by country and total population

\begin{tabular}{|c|c|c|c|c|c|c|c|}
\hline & $\begin{array}{l}\text { Milk and } \\
\text { derivates }\end{array}$ & $\begin{array}{l}\text { Hot } \\
\text { beverages }\end{array}$ & Juices & $\begin{array}{l}\text { Regular sweetened } \\
\text { beverages }\end{array}$ & $\begin{array}{l}\text { Diet } \\
\text { beverages }\end{array}$ & $\begin{array}{l}\text { Alcoholic } \\
\text { beverages }\end{array}$ & $\begin{array}{l}\text { Total fluid } \\
\text { intake }\end{array}$ \\
\hline $\begin{array}{l}\text { Mexico } \\
\quad(n=1498)\end{array}$ & $200(189,211)$ & $25(23,27)$ & $80(74,86)$ & $232(220,243)$ & $3(2,3)$ & $25(19,30)$ & $565(547,583)$ \\
\hline $\begin{array}{l}\text { Brazil } \\
\qquad(n=1924)\end{array}$ & $220(208,232)$ & $62(57,66)$ & $216(207,225)$ & $82(76,89)$ & $1(1,1)$ & $113(98,129)$ & $694(672,716)$ \\
\hline $\begin{array}{l}\text { Argentina } \\
\quad(n=507)\end{array}$ & $168(153,183)$ & $184(172,197)$ & $123(108,139)$ & $147(124,170)$ & $27(23,31)$ & ND & $649(622,676)$ \\
\hline Spain $(n=1240)$ & $108(96,119)$ & $61(58,64)$ & $42(38,47)$ & $63(56,69)$ & $5(4,7)$ & $149(135,164)$ & $428(408,447)$ \\
\hline France $(n=1534)$ & $66(59,73)$ & $78(75,82)$ & $27(25,29)$ & $52(48,57)$ & $4(3,5)$ & $95(87,103)$ & $329(318,340)$ \\
\hline $\mathrm{UK}(n=897)$ & $98(86,110)$ & $205(196,215)$ & $54(48,60)$ & $151(138,164)$ & $\mathrm{ND}^{\mathrm{a}}$ & $148(132,164)$ & $656(633,679)$ \\
\hline $\begin{array}{l}\text { Germany } \\
\quad(n=1868)\end{array}$ & $299(279,318)$ & $138(133,143)$ & $81(75,88)$ & $108(100,116)$ & $2(1,2)$ & $187(174,199)$ & $817(792,842)$ \\
\hline Poland $(n=1062)$ & $83(76,91)$ & $146(142,150)$ & $41(38,45)$ & $70(65,76)$ & $\mathrm{ND}^{\mathrm{a}}$ & $76(68,84)$ & $415(401,428)$ \\
\hline Turkey $(n=961)$ & $65(56,74)$ & $102(97,107)$ & $55(48,62)$ & $85(77,94)$ & $0(0,1)$ & $8(5,12)$ & $314(298,330)$ \\
\hline $\operatorname{Iran}(n=572)$ & $182(167,196)$ & $102(97,107)$ & $29(26,32)$ & $50(44,56)$ & $2(1,2)$ & ND & $365(347,383)$ \\
\hline China $(n=1466)$ & $110(103,117)$ & $91(83,98)$ & $9(8,11)$ & $41(36,45)$ & $\mathrm{ND}^{\mathrm{a}}$ & $69(59,79)$ & $320(305,336)$ \\
\hline $\begin{array}{l}\text { Indonesia } \\
\quad(n=1366)\end{array}$ & $48(41,54)$ & $52(48,55)$ & $8(6,9)$ & $74(64,84)$ & $\mathrm{ND}^{\mathrm{a}}$ & ND & $182(170,194)$ \\
\hline $\operatorname{Japan}(n=1381)$ & $84(77,90)$ & $151(146,155)$ & $26(24,29)$ & $40(36,44)$ & $\mathrm{ND}^{\mathrm{a}}$ & $159(146,172)$ & $460(444,475)$ \\
\hline $\begin{array}{l}\text { Total population } \\
(n=16,276)\end{array}$ & $140(137,144)$ & $99(97,101)$ & $64(62,66)$ & $91(88,93)$ & $2(2,3)$ & $91(87,94)$ & $490(483,496)$ \\
\hline
\end{tabular}

Data expressed as mean $(95 \% \mathrm{CI})$

$N D$ no data

${ }^{a}$ In case of UK, Poland, China, Indonesia and Japan, the intake of diet beverages was included in the regular sweetened beverages category

and $102 \mathrm{kcal} /$ day, respectively). In Mexico and Indonesia, the highest energy intake from fluids came from RSB (232 and $74 \mathrm{kcal} /$ day, respectively). Significant gender difference in energy intake provided by the different fluid types was also observed (Supplementary Table 3). In the total sample, men had a significantly higher mean energy intake from RSB and alcoholic beverages than women. Women on the other hand had a higher energy intake provided by milk and derivatives than men.

Figure 2 shows the proportion of participants exceeding the WHO recommendation on energy intake provided by free sugar, solely by the intake of fluids. The highest proportion 


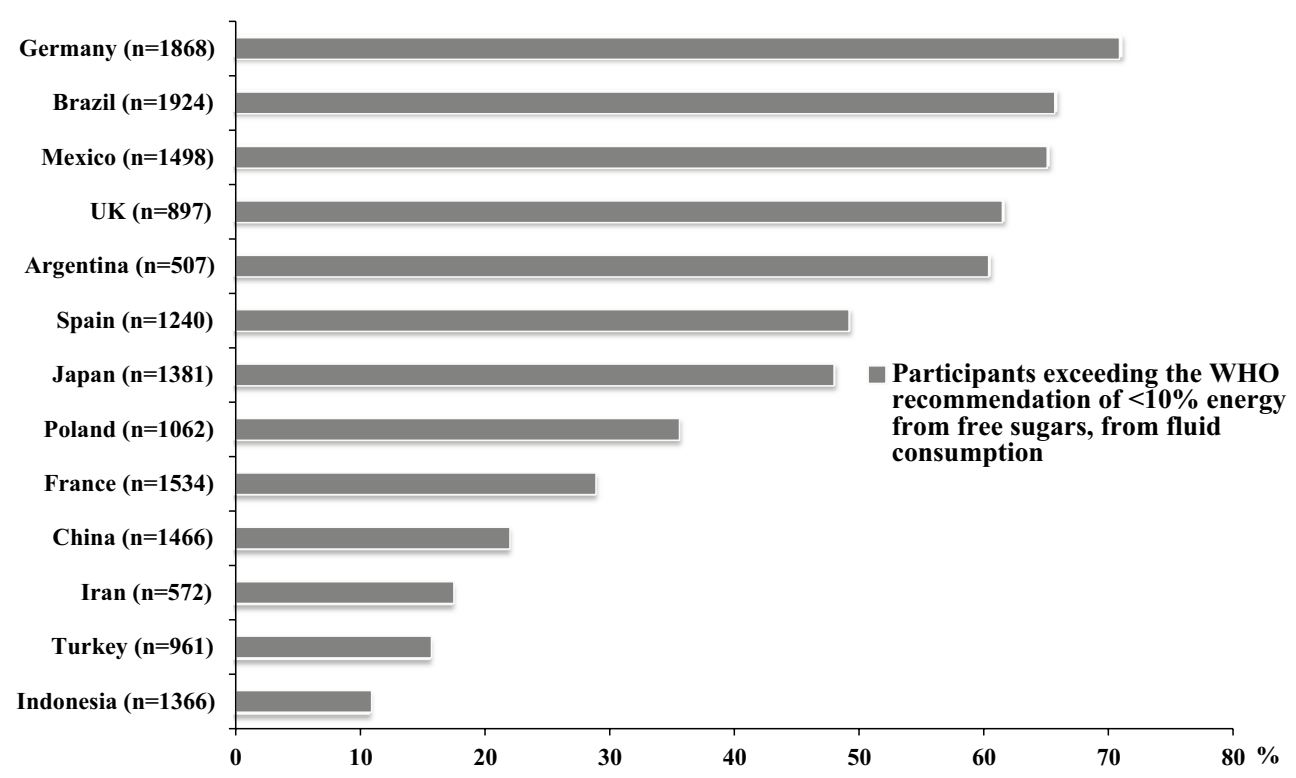

Fig. 2 Participants exceeding WHO recommendations for free sugar ( $<10 \%$ of energy), considering only fluid intake

of adults exceeding the WHO recommendation was observed in Germany (70.9 \%), followed by Brazil (65.7\%), Mexico (65.1\%), UK (61.5\%) and Argentina (60.4\%), whereas the lowest proportion was observed in Indonesia (10.9 \%). Considering all countries together, $44.5 \%$ of the population exceeded the WHO recommendations on energy intake provided by free sugar, solely by fluids.

\section{Discussion}

The aim of the present analysis was to collate and describe the intake of water and all other fluids of adults of 13 crosssectional surveys, which used the same 7-day fluid-specific record. This unique compilation of national surveys conducted in large sample of participants from different countries demonstrated that not only the volume, but also the contribution of the different fluid types to TFI varied substantially between countries. Nevertheless, some countries that seemed to be geographically linked share similar patterns. The fluid intake of the countries relatively close to the Mediterranean Sea (Spain, France, Turkey and Iran) and also the two Asian countries (Indonesia and China) was characterised by a high contribution of water to TFI, ranging from 47 to $78 \%$. In North European countries (UK, Poland and Germany), the highest contribution to TFI came from hot beverages. The fluid intake of the three countries of Latin America was characterised by a high contribution of juices and RSB, which is as important as the contribution of water to TFI. Due to these substantial inter-geographical area differences in fluid intake contribution, the pooled data of all countries should be interpreted with caution. Identifying factors that could explain these observed between-country differences was not the aim of the current analysis, yet several hypotheses can be made. One of the possible factors explaining the between-country differences is climate and seasonality. Studies analysing seasonality of fluid intake indicated that temperature and seasons affected both volume and choice of beverages type [36]. However, Tani et al. [37] reported that in China an increase of $1{ }^{\circ} \mathrm{C}$ in the mean outdoor air temperature on the survey day was associated with an increased intake of water from fluids by only $8.4 \mathrm{~mL} /$ day $(P<0.0001)$ and that the influence of humidity was non-significant. Therefore, it seems unlikely that the differences observed between countries in volumes of beverage can be explained by climate alone. The impact of seasonality on the reported fluid intake between countries cannot be evaluated in this study, because in each survey data collection took place once during a period of the year with a mild climate (spring or autumn). Other factors to take into consideration when assessing the between-country variability are cultural and traditional habits, which unfortunately were not evaluated in the present study.

The data in the current analysis are in line with data reported in other published surveys. The fluid intake pattern with a high contribution of water to TFI characteristically for the Mediterranean countries was also reported in France by Bellisle et al. [39] and in Italy by Leclercq et al. [38]. Even though Bellisle et al. [39] reported a lower TFI and a higher intake of milk and alcoholic beverages in French adults than observed in our French survey, a pattern characterised by a relatively high contribution of water ( $43 \%)$ and hot beverages $(20 \%)$ was also observed. Furthermore, 
a high contribution of water to TFI (58\% in men and $67 \%$ in women) was also observed among Italian adults [38]. Although Italy was not included in the current analysis, this beverage pattern was similar than that we observed among the countries relatively close to the Mediterranean Sea.

The intake of the North European countries in the current surveys was characterised by a high intake of hot beverages. The National Nutritional Survey II assessed food intake of 15,371 German adults confirmed a similar contribution of hot beverages $(21 \%)$ to TFI, even though they reported higher volumes of all fluid types and a higher contribution of water to TFI ( 42 vs. $32 \%$ in the present study) than in the current analysis. The contribution of juices and RSB to TFI observed in the present analysis was also different compared with others surveys [40]. These differences can be explained in part because in the present study these fluid types were split; however, the combined contribution (juices plus RSB) of $20 \%$ is comparable to the $17 \%$ observed in previous studies. For the UK, two previously published surveys reported TFI volumes and energy intake provided by beverages among adults that were in line with our observations [22, 41]. A survey performed in another North European country not included in the current analysis, Finland, also showed a fluid intake pattern characterised by a high contribution of water ( 34 and $51 \%$ for men and women, respectively) and hot beverages (39 and $37 \%$ for men and women, respectively) to TFI [42].

In Latin American countries, publications reporting fluid intake in adults were mainly focussed on the intake of caloric beverages and covered only the Mexican population $[43,44]$. These two Mexican surveys described volumes of intake for the different fluid categories comparable to those in the current analysis. However, in both studies mean energy intake from fluids (372 and $382 \mathrm{kcal} /$ day/per capita, respectively) was estimated to be lower than that estimated in the present study, which could be probably explained by a different classification of the beverages and the use of different food composition data.

The results obtained in the present international survey highlight the need to educate adults about the nutritional composition of the different fluids. As observed in previous studies, an accurate education programme and public health actions would be effective to encourage regular consumers to decrease their RSB consumption with water or other non-caloric beverages, in order to decrease the risk of chronic disease such as type 2 diabetes [23, 45] or overweight/obesity [7]. Attention should also be paid to fruit juices, because adult individuals still perceive beverages such as squashes, fruit lemonades and fruit sodas as a healthy option, and they should be advised about the low fruit content and the higher amounts of sugar [46]. In this present analysis, juices and RSB were separated into two different categories, because the nutritional composition is different. $100 \%$ fruit juices could potentially contribute to daily vitamin and antioxidants intake [47]. However, regarding sugar content, RSB and juices are comparable; therefore, an increased intake should not be encouraged.

Several limitations of the fluid surveys or the current analysis need to be discussed. As often happens in nutritional research, the self-reported surveys collecting the intake of fluids are open to potential bias due to the overor under-reporting of certain fluid types. This limitation can also be related to the current analysis, even though the same 7-day fluid-specific record was used in all the surveys. Another limitation was that the classification of diet beverages was not performed in the same way in all countries and alcoholic beverages were not recorded in some surveys, which limited the comparison between countries. Sugar and energy content per $100 \mathrm{~mL}$ of fluid type was used for the estimation of the energy and sugar consumed from each beverage in all countries. These were an approximate estimation of the reality, since the same fluid type of the same brand can have a different nutritional composition depending on the country. Additionally, sugar or other ingredients added by the consumer to the fluids were not taken into account for the calculation of energy intake. Therefore, the energy intake from fluids is likely to be underestimated. For the evaluation of the percentage of energy provided by free sugar, total energy intake had to be estimated since no food data were collected. The lack of food data also limited the interpretation of the data on energy intake from fluids. However, evidence suggested that a fluid-specific record might more accurately estimate fluid intake compared with a food and fluid record [48]. Since the primary aim of all 13 surveys included was to assess fluid intake, the preference was given to record fluids only. Due to the lack of anthropometric data of the participants in certain countries, the calculations had to be based on population means of energy intake. Nevertheless, this assumption was considered to be acceptable in epidemiological studies since the individual surveys aimed at collecting data from a nationally large sample of individuals and also because the energy intake data for the food balance sheets were recorded during the same year of the fluid surveys.

Despite these methodological limitations, this analysis has several strengths. This analysis is unique as it collated data of 13 surveys with relatively large sample sizes and an equal distribution between both genders. The compilation also contains original data from countries, which previously had no internally published fluid intake data available. The third strength is the use of the same 7-day fluidspecific diary in all the surveys that was also supported by a photographic booklet to limit the self-reporting error. Finally, the intake of drinking water and all other fluids were reported, in the 13 surveys except alcoholic beverages 
in three countries. This is rather exceptional as shown in the systematic review by Özen et al. [26].

In conclusion, the current study shows that intake volumes of the different fluid types differ considerably between countries, but these differences in the contribution to TFI are modest between countries of the same geographical area. Even though the highest volume consumed was recorded for drinking water, the mean energy intake from fluids was higher than expected due to the high consumption of RSB and fruit juices (reached up to $694 \mathrm{kcal} /$ day of energy intake on average). Since the proportion of adults exceeding the WHO recommendation for energy intake provided by free sugars ranged from 11 up to $70.9 \%$, educating adults about the nutritional composition of the different fluids seems a pertinent step but not only one in terms of public health. Health authorities and food industry should take complementary actions to promote fluids with low sugar content and to create an environment favouring water consumption.

Acknowledgments Data collected were performed by the Center of Disease Control in China; the National Nutrition and Food Technology Research Institute in Iran. We acknowledge Christine Jean, Market Research and Consumer Intelligence Danone Waters and the entire MRCI Team for having raised the methodology of fluid intake surveys to the current standard and for having guided IPSOS (in Mexico, UK and Turkey), TNS (in Argentina, France, Germany, Poland and Spain), Nielsen (in Indonesia), and GFK (in Brazil) for the preparation of the survey. All the participants give their consent prior the inclusion in the study. The protocol of the unpublished surveys was reviewed and approved by the Institutional Review Board, Office of Research Compliance of the University of Arkansas (IRB Protocol \# 14-12-376). The Chinese surveys were approved by the Ethical Review Committee of the National Institute for Nutrition and Food Safety, Chinese Center for Disease Control and Prevention. All data were recorded anonymously.

Conflict of interest IG is an employee of Danone Research. JS-S, JS, LAM, SK, JG, HM are members of advisory board on fluid intake of Danone Research. S.A.K. has received research grants from Danone Research. B.S. has received research grant from R\&D AQUA Group, Indonesia. A.M and N.E. are employer at NNFTRI, an instituted which has received a research grant from Damavand mineral water company (a brand of Danone Group in Iran). J.S.-S. and N.B. have received consultancies from Danone S.A. C.F.-P. and J.A. report no conflict of interest.

Open Access This article is distributed under the terms of the Creative Commons Attribution 4.0 International License (http://creativecommons.org/licenses/by/4.0/), which permits unrestricted use, distribution, and reproduction in any medium, provided you give appropriate credit to the original author(s) and the source, provide a link to the Creative Commons license, and indicate if changes were made.

\section{References}

1. Curhan GC, Willett WC, Knight EL, Stampfer MJ (2004) Dietary factors and the risk of incident kidney stones in younger women: nurses' Health Study II. Arch Intern Med 164:885-891
2. Clark WF, Sontrop JM, Macnab JJ, Suri RS, Moist L, Salvadori M, Garg AX (2011) Urine volume and change in estimated GFR in a community-based cohort study. Clin J Am Soc Nephrol 6:2634-2641

3. Roussel R, Fezeu L, Bouby N, Balkau B, Lantieri O, AlhencGelas F, Marre M, Bankir L (2011) Low water intake and risk for new-onset hyperglycemia. Diabetes Care 34:2551-2554

4. Enhörning S, Struck J, Wirfält E, Hedblad B, Morgenthaler NG, Melander O (2011) Plasma copeptin, a unifying factor behind the metabolic syndrome. J Clin Endocrinol Metab 96:E1065-E1072

5. Sontrop JM, Dixon SN, Garg AX, Buendia-Jimenez I, Dohein O, Huang SH, Clark WF (2013) Association between water intake, chronic kidney disease, and cardiovascular disease: a cross-sectional analysis of NHANES data. Am J Nephrol 37:434-442

6. World Health Organisation (2015) Guideline: sugar intake for adults and children. World Health Organisation, Geneva

7. Te Morenga L, Mallard S, Mann J (2013) Dietary sugars and body weight: systematic review and meta-analyses of randomised controlled trials and cohort studies. BMJ 346:e7492. doi:10.1136/bmj.e7492

8. Trumbo PR, Rivers CR (2014) Systematic review of the evidence for an association between sugar-sweetened beverage consumption and risk of obesity. Nutr Rev 72:566-574

9. Malik VS, Pan A, Willett WC, Hu FB (2013) Sugar-sweetened beverages and weight gain in children and adults: a systematic review and meta-analysis. Am J Clin Nutr 98:1084-1102

10. Vartanian LR, Schwartz MB, Brownell KD (2007) Effects of soft drink consumption on nutrition and health: a systematic review and meta-analysis. Am J Public Health 97:667-675

11. Tate DF, Turner-McGrievy G, Lyons E, Stevens J, Erickson K, Polzien K, Diamond M, Wang X, Popkin B (2012) Replacing caloric beverages with water or diet beverages for weight loss in adults: main results of the Choose Healthy Options Consciously Everyday (CHOICE) randomized clinical trial. Am J Clin Nutr 95:555-563

12. Pan A, Malik VS, Hao T, Willett WC, Mozaffarian D, Hu FB (2013) Changes in water and beverage intake and long-term weight changes: results from three prospective cohort studies. Int J Obes (Lond) 37:1378-1385

13. Peters JC, Wyatt HR, Foster GD, Pan Z, Wojtanowski AC, Vander Veur SS, Herring SJ, Brill C, Hill JO (2014) The effects of water and non-nutritive sweetened beverages on weight loss during a 12-week weight loss treatment program. Obesity (Silver Spring) 22:1415-1421

14. Dennis EA, Dengo AL, Comber DL, Flack KD, Savla J, Davy KP, Davy BM (2010) Water consumption increases weight loss during a hypocaloric diet intervention in middle-aged and older adults. Obesity (Silver Spring) 18:300-307

15. Barrio-Lopez MT, Martinez-Gonzalez MA, Fernandez-Montero A, Beunza JJ, Zazpe I, Bes-Rastrollo M (2013) Prospective study of changes in sugar-sweetened beverage consumption and the incidence of the metabolic syndrome and its components: the SUN cohort. Br J Nutr 110:1722-1731

16. Denova-Gutierrez E, Talavera JO, Huitron-Bravo G, MendezHernandez P, Salmeron J (2010) Sweetened beverage consumption and increased risk of metabolic syndrome in Mexican adults. Public Health Nutr 13:835-842

17. Malik VS, Popkin BM, Bray GA, Despres JP, Willett WC, Hu FB (2010) Sugar-sweetened beverages and risk of metabolic syndrome and type 2 diabetes: a meta-analysis. Diabetes Care 33:2477-2483

18. Yoo S, Nicklas T, Baranowski T, Zakeri IF, Yang SJ, Srinivasan SR, Berenson GS (2004) Comparison of dietary intakes associated with metabolic syndrome risk factors in young adults: the Bogalusa Heart Study. Am J Clin Nutr 80:841-848 
19. The InterAct consortium (2013) Consumption of sweet beverages and type 2 diabetes incidence in European adults: results from EPIC-InterAct. Diabetologia 56:1520-1530

20. Malik AH, Akram Y, Shetty S, Malik SS, Yanchou NV (2014) Impact of sugar-sweetened beverages on blood pressure. Am J Cardiol 113:1574-1580

21. Stanhope KL, Medici V, Bremer AA, Lee V, Lam HD, Nunez MV, Chen GX, Keim NL, Havel PJ (2015) A dose-response study of consuming high-fructose corn syrup-sweetened beverages on lipid/lipoprotein risk factors for cardiovascular disease in young adults. Am J Clin Nutr. doi:10.3945/ajen.114.100461

22. Gibson S, Shirreffs SM (2013) Beverage consumption habits "24/7" among British adults: association with total water intake and energy intake. Nutr J 12:9-21

23. Panahi S, El KD, Luhovyy BL, Goff HD, Anderson GH (2013) Caloric beverages consumed freely at meal-time add calories to an ad libitum meal. Appetite 65:75-82

24. Kant AK, Graubard BI, Mattes RD (2012) Association of food form with self-reported 24-h energy intake and meal patterns in US adults: NHANES 2003-2008. Am J Clin Nutr 96:1369-1378

25. Mathers C, Loncar D (2006) Projections of global mortality and burden of disease from 2002 to 2030. PLoS Med 3:e442

26. Ozen AE, Bibiloni MD, Pons A, Tur JA (2014) Fluid intake from beverages across age groups: a systematic review. J Hum Nutr Diet. doi:10.1111/jhn.12250

27. Martinez H (2014) Fluid intake in Mexican adults; a cross-sectional study. Nutr Hosp 29:1179-1187

28. Ferreira-Pego C, Babio N, Fenandez-Alvira JM, Iglesia I, Moreno LA, Salas-Salvado J (2014) Fluid intake from beverages in Spanish adults; cross-sectional study. Nutr Hosp 29:1171-1178

29. Gandy J (2012) First findings of the United Kingdom fluid intake study. Nutr Today 47:S14-S16

30. Abdollahi M, Naseri E, Bondariazadeh D, Monhammadpour B, Houshiar-rad N (2013) Types and amounts of fluids consumed by the adult population of Tehran, 2011. Iran J Nutr Sci Food Technol 8:70-80

31. Ma G, Zhang Q, Liu A, Zuo J, Zhang W, Zou S, Li X, Lu L, Pan H, Hu X (2012) Fluid intake of adults in four Chinese cities. Nutr Rev 70(Suppl 2):S105-S110

32. Ferreira-Pego C, Guelinckx I, Moreno LA, Kavouras S, Gandy J, Martinez H, Bardosono S, Abdollahi M, Naseri E, Jarosz A, Babio N, Salas-Salvado J (2015) Total fluid intake and its determinants: cross sectional surveys among adults in 13 countries worldwide. Eur J Nutr. doi:10.1007/s00394-015-0943-9

33. United States Department of Agriculture (USDA) and Agricultural Research Service (2014) National nutrient database for standard reference release 27. http://ndb.nal.usda.gov/ndb/ search. Accessed 12 Dec 2014

34. Food and Agriculture Organisation (FAO) of the United Nations and Statistics Division (2014) Food balance sheets. http:// faostat3.fao.org/browse/FB/FBS/E. Accessed 12 Dec 2014

35. Institute of Medicine, Food and Nutrition Board (2002) Dietary reference intakes for energy, carbohydrate, fiber, fat, fatty acids, cholesterol, protein and amino acids. The National Academies Press, Washington DC

36. Malisova O, Bountziouka V, Panagiotakos DB, Zampelas A, Kapsokefalou M (2013) Evaluation of seasonality on total water intake, water loss and water balance in the general population in Greece. J Hum Nutr Diet 26(Suppl 1):90-96

37. Tani Y, Asakura K, Sasaki S, Hirota N, Notsu A, Todoriki H, Miura A, Fukui M, Date C (2015) The influence of season and air temperature on water intake by food groups in a sample of free-living Japanese adults. Eur J Clin Nutr. doi:10.1038/ ejcn.2014.290

38. Leclercq C, Arcella D, Piccinelli R, Sette S, Le DC, Turrini A (2009) The Italian National Food Consumption Survey INRANSCAI 2005-06: main results in terms of food consumption. Public Health Nutr 12:2504-2532

39. Bellisle F, Thornton SN, Hebel P, Denizeau M, Tahiri M (2010) A study of fluid intake from beverages in a sample of healthy French children, adolescents and adults. Eur J Clin Nutr 64:350-355

40. Max Rubner Institut (2008) National food intake study II. Countrywide assessment of nutrition in adolescents and adults. Federal Research Institute for Nutrition and Food Karlsruhe

41. Ng SW, Ni MC, Jebb SA, Popkin BM (2012) Patterns and trends of beverage consumption among children and adults in Great Britain, 1986-2009. Br J Nutr 108:536-551

42. Paturi M, Tapanainen H, Reinivue H, Pietinen P (2008) The National FINDIET 2007 Survey. Department of Health Promotion and Chronic Disease Prevention, Nutrition Unit, National Public Health Institute publications, Helsinki

43. Barquera S, Hernandez-Barrera L, Tolentino ML, Espinosa J, Ng SW, Rivera JA, Popkin BM (2008) Energy intake from beverages is increasing among Mexican adolescents and adults. J Nutr 138:2454-2461

44. Stern D, Piernas C, Barquera S, Rivera JA, Popkin BM (2014) Caloric beverages were major sources of energy among children and adults in Mexico, 1999-2012. J Nutr 144:949-956

45. Pan A, Malik VS, Schulze MB, Manson JE, Willett WC, Hu FB (2012) Plain-water intake and risk of type 2 diabetes in young and middle-aged women. Am J Clin Nutr 95:1454-1460

46. Bucher T, Siegrist M (2015) Children's and parents' health perception of different soft drinks. Br J Nutr 113:526-535

47. O'Neil CE, Nicklas TA, Rampersaud GC, Fulgoni VL III (2012) $100 \%$ orange juice consumption is associated with better diet quality, improved nutrient adequacy, decreased risk for obesity, and improved biomarkers of health in adults: National Health and Nutrition Examination Survey, 2003-2006. Nutr J 11:107. doi:10.1186/1475-2891-11-107

48. Bardosono S, Monrozier R, Permadhi I, Manikam N, Rohan R, Guelinckx I (2015) Total fluid intake assessed with a 7-day fluid record versus a 24 -h dietary recall: a crossover study in Indonesian adolescents and adults. Eur J Nutr. doi:10.1007/ s00394-015-0954-6 